\title{
Synthesis and Characterization of Polypropylene-based Polyurethanes
}

Hanqing Jiang, ${ }^{t, \neq}$ Lin Ye, ${ }^{+}$Yanhui Wang, ${ }^{,+}$Li Ma, ${ }^{\dagger}$ Dongmei Cui, ${ }^{\dagger}$ and Tao $\operatorname{Tang}^{*},+, \neq$

$\dagger$ State Key Laboratory of Polymer Physics and Chemistry, Changchun Institute of Applied Chemistry, Chinese Academy of Sciences, Changchun 130022, China

†University of Science and Technology of China, Anhui 230026, China 


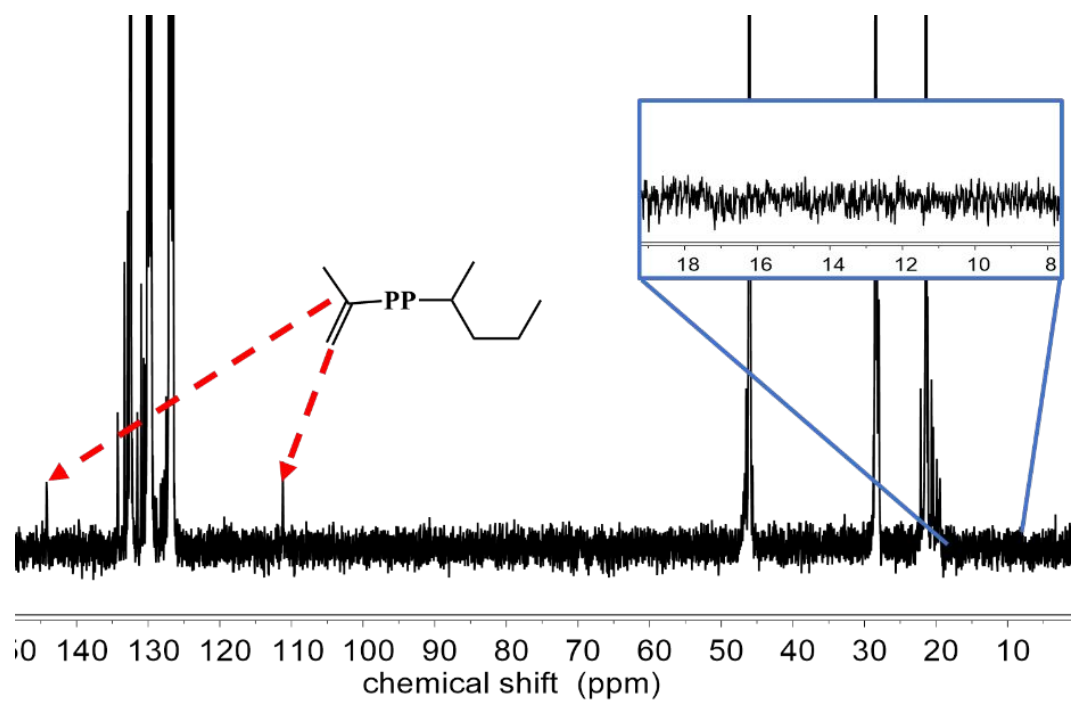

Figure S1. ${ }^{13} \mathrm{C}$-NMR $\left(400 \mathrm{MHz}, 110{ }^{\circ} \mathrm{C}, \mathrm{C}_{6} \mathrm{D}_{4} \mathrm{Cl}_{2}\right)$ of PP-TVD

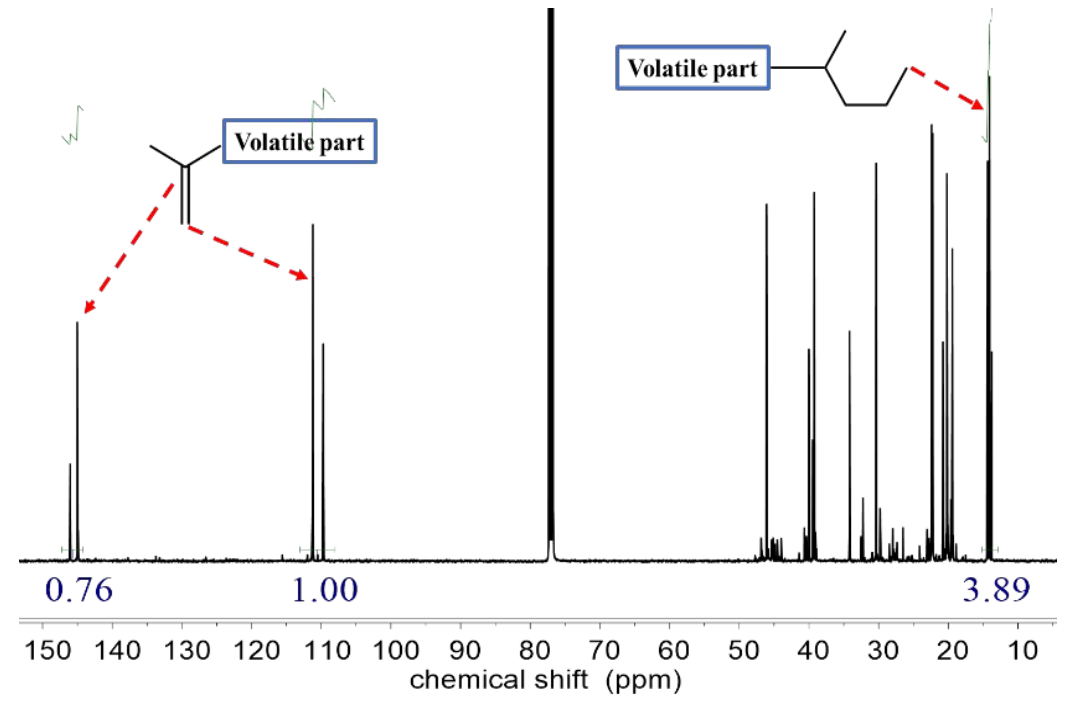

Figure S2. ${ }^{13} \mathrm{C}-\mathrm{NMR}\left(400 \mathrm{MHz}, 110{ }^{\circ} \mathrm{C}, \mathrm{C}_{6} \mathrm{D}_{4} \mathrm{Cl}_{2}\right)$ of the volatile product from PP pyrolysis 


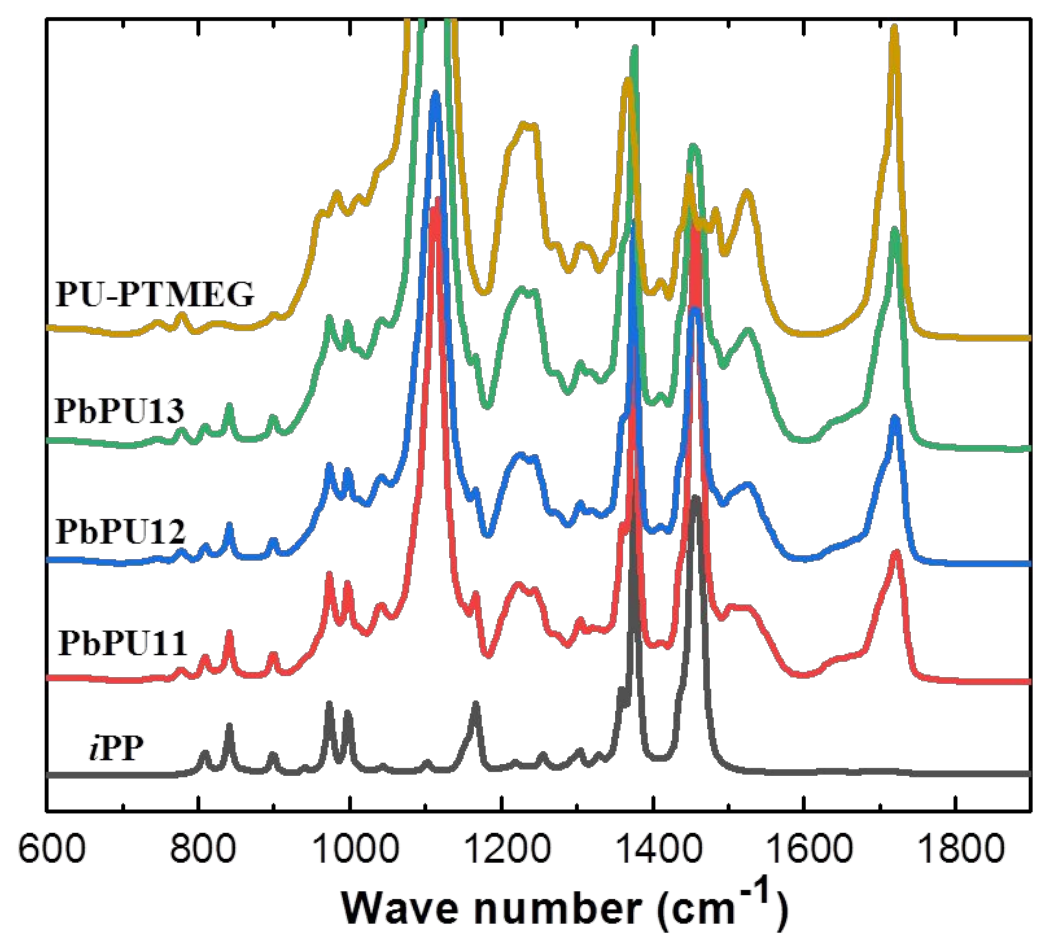

Figure S3. FTIR spectra of PbPU copolymers, PU-PTMEG and PP samples

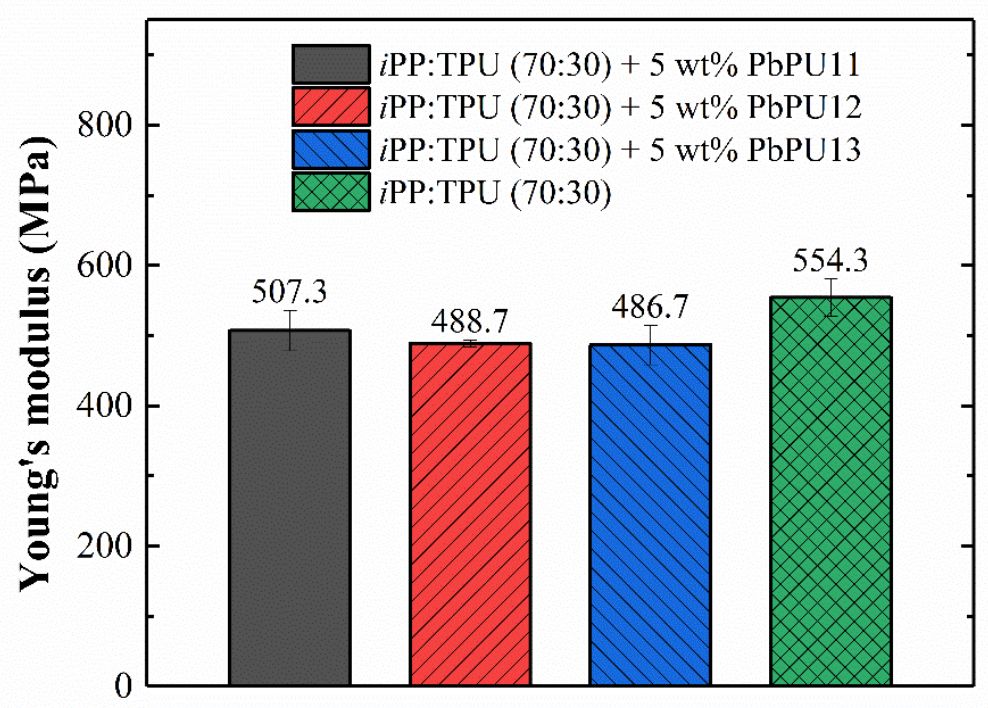

Figure S4. Young's modulus of $i \mathrm{PP} / \mathrm{TPU}=70 / 30$ blends compatibilized by PbPUs 

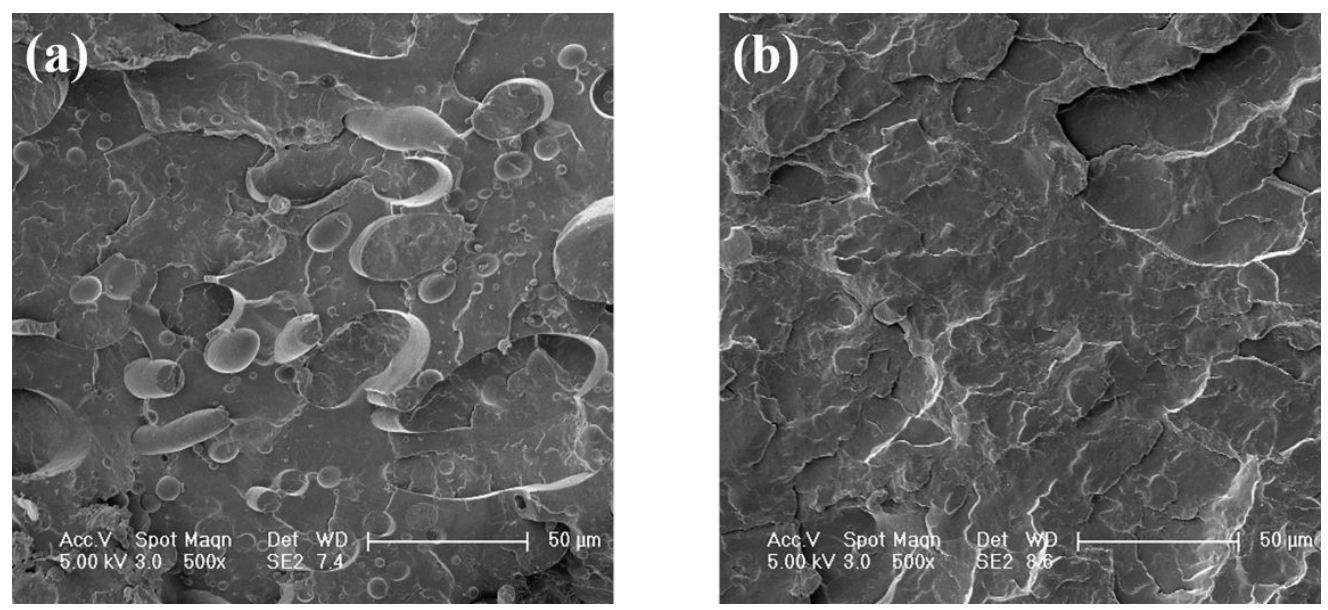

Figure S5. SEM images of the cryo-fractured surface of 30/70 RP/TPU blends

(a) without and (b) with $5 \mathrm{wt} \% \mathrm{PbPU} 11$.
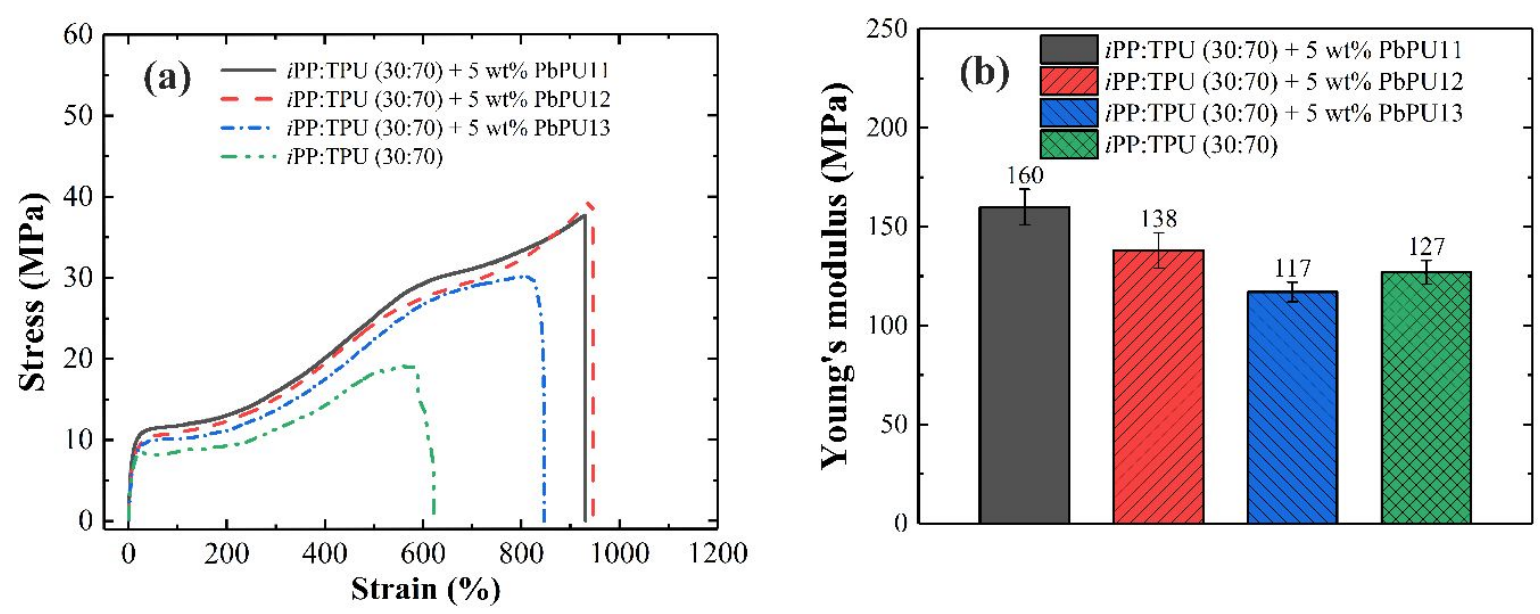

Figure S6. (a) Stress-strain curves and (b) young's modulus of PP/TPU $=30 / 70$ blends compatibilized by PbPUs. 


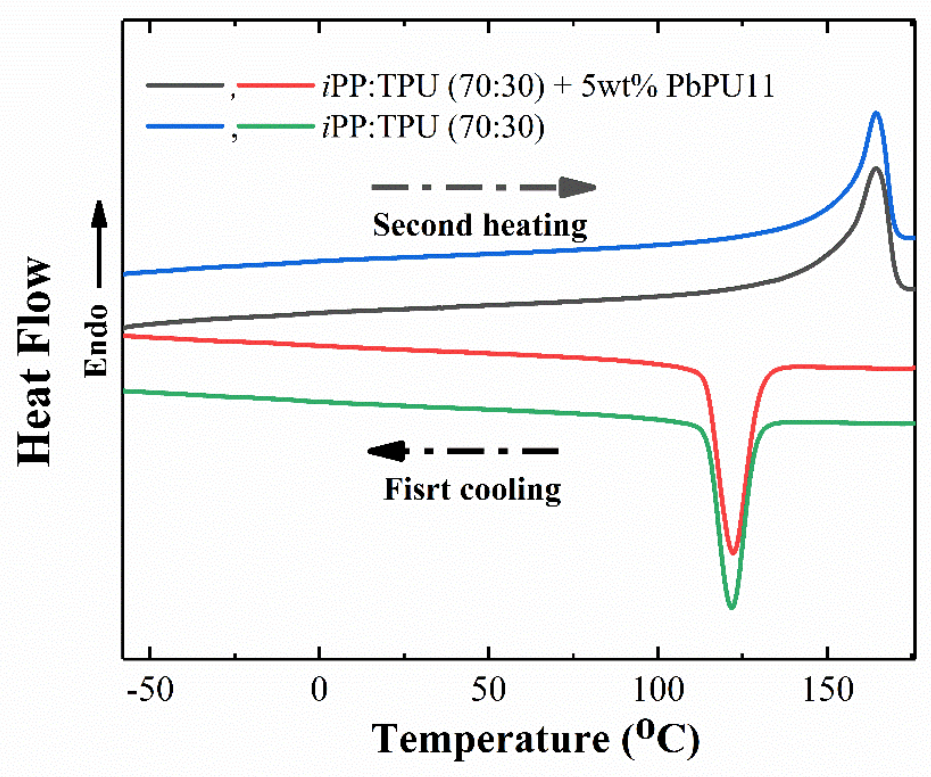

Figure S7. DSC curves of $i \mathrm{PP} / \mathrm{TPU}=70 / 30$ blends before and after compatibilization

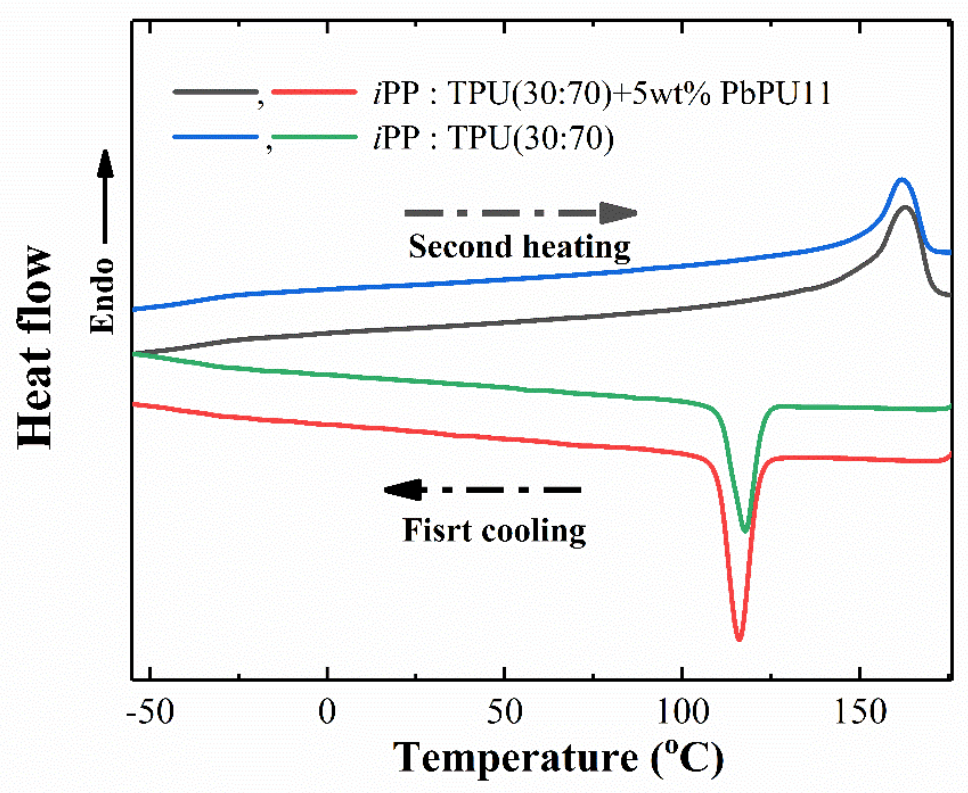

Figure S8. DSC curves of $i \mathrm{PP} / \mathrm{TPU}=30 / 70$ blends before and after compatibilization 